\section{Proposal divides biologists}

\section{London}

BrITAIN's biology community is divided on the merits of the new plan to restructure biology teaching and research in universities (see Nature 338,363; 30 March 1989). Some are resigned to the plan, others will strive to persuade the Universities Funding Council (UFC) to modify some of the proposals.

The report, distributed to universities last week, was carried out for the University Grants Committee (which was dissolved last week) by a group led by Professor Sir Richard Southwood of the University of Oxford. It was the subject of heated discussion at the first meeting on 31 March of a new group comprising more than 50 heads of biology departments.

The most controversial aspect of the plan is the proposal to group existing

\section{Phobos failure raises doubts}

\section{London}

THE failure last week of Phobos-2, the second of the two Soviet Mars probes launched last July, could hardly have been worse timed for Soviet space planners. During the past few months, there has been growing public criticism in the Soviet Union of the cost of space, particularly of deep-space missions with no obvious economic spin-off. One of the chief advocates of swingeing cuts in the space budget is $\mathrm{Mr}$ Boris Yeltsin, who on 26 March won a resounding election victory over the 'official' candidate. The following day, contact with Phobos-2 was lost.

The two-craft Phobos mission included a wide range of investigations of Mars and its satellite Phobos, including the firing of a laser at Phobos and the landing of a 'hopping' probe to investigate the satellite's surface. It carried experiments from 13 countries and multinational agencies and had been presented as a first step to an international manned mission to Mars early in the next century. But Soviet media coverage of the mission has from the beginning been tentative.

The original mission consisted of two spacecraft, carrying different experiments. Early in September, Phobos-1 came to grief when a ground-based computer error led to its being sent an incorrect command. In December, the main transmitter on Phobos-2 failed, but the craft arrived on schedule and on 23 January was inserted into an orbit around Mars. It functioned as planned for the next nine weeks, returning several photographs of the surface of Mars and Phobos.

On 27 March, the command to rotate the probe to prepare for the close (50-m) transit of Phobos was apparently followed correctly - but mission control found it impossible to re-establish contact. Two days later, the head of the Glavkosmos space agency said his experts were working round the clock to try to restore the links. But these efforts proved fruitless.

Although Soviet newspapers have made the best of the photographs and data already received from Phobos-2, these are unlikely to restore public confidence. But as Pravda revealed last week, there is equal resentment that it will be a Japanese journalist (paying his fare in hard currency) and not a Soviet citizen who will be the first media representative to visit the Mir station (see this page). Vera Rich JAPAN IN SPACE

\section{Journalist plans scoop}

Tokyo

Thanks to the Soviet Union, the first Japanese citizen to journey into space may be a journalist from a private television network rather than one of the astronauts training for a ride on the US space shuttle.

Last week, the Tokyo Broadcasting System (TBS) network signed an agreement with the Soviet Commission for Space Exploration (Glavkosmos) that will allow a TBS reporter to spend six days aboard the Mir space station in 1991. The reporter will make live broadcasts to Japan every day throughout his stay in the station.

The agreement comes as a shock to Japan's National Space Development Agency (NASDA), which has been planning for years to put the first Japanese astronaut in space aboard the US space shuttle. Although a final date for the reporter's space voyage has yet to be set, TBS has arranged the flight to commemorate the network's 40th anniversary on 10 May 1991. There is thus a strong possibility that TBS will 'scoop' NASDA's plans to put an astronaut on the space shuttle in July of the same year.

Soviet journalists are also upset about the agreement. Pravda, the Communist party daily newspaper, welcomed the Soviet authorities' decision to offer a journalist a space flight but complained that only foreigners could afford to pay the fare. The Communist Party youth newspaper Komsomolskaya Pravda carried, under the headline "Prestige trampled underfoot", pictures of Yuri Gagarin, the first man in space, Valentina Tereshkova, the first woman in space, and a Japanese 10,000yen banknote with the caption "The first journalist in space?”. David Swinbanks departments into two kinds of much larger departments, one focusing on molecular biology and the other on more traditional areas such as ecology and evolutionary studies. This was criticized as "disastrous", "illogical" and "an odd reversal of the current trend towards integrative biology" One speaker said it would divorce the techniques of molecular biology from the subject areas in which they were being applied. The department heads agreed that a rigid division between the two types of department would be detrimental.

On the other hand, they disagreed over interpretation of the report, some saying it was too dogmatic and others insisting that there would be flexibility.

The proposal to group all biology departments in a university into a single school of biological sciences was also welcomed. Most agreed that fragmentation is undesirable, but the report was criticized for putting forward only one model for integration. The group agreed that for different universities, different strategies would be necessary.

The group also agreed with the recommendation that pre-clinical teaching of biology in schools of medicine, dentistry and veterinary science should be the responsibility of the new schools of biological sciences. Professor James Callow, of the University of Birmingham, described this as the "most radical proposal" in the plan, but the review committee was criticized for not studying this problem in more detail. This proposal is likely to meet fierce opposition in medical schools.

The biology heads were particularly concerned about the effects on biology of the planned restructuring of other sciences. Although the biology plan recommends no closures, the expected closure of more than ten university chemistry departments is expected to have a knockon effect on biology.

There was also concern about the future quality of entrants into university biology courses. Changes in the content of school examinations are likely to mean that students have less factual knowledge in the sciences. The biology heads also fear that the courses provided at British universities may compare badly with more comprehensive and longer courses at other European universities. One proposed solution to both these problems was that England should follow Scotland in introducing 4-year degree courses. instead of the present 3-year courses.

The committee elected by the new group of heads will put a response to the biology report formally to the new Universities Funding Council later this month. This report was intended to be only the precursor to a more wide-ranging review, but was carried out quickly so that restructuring of biology would not lag too far behind restructuring in the other sciences.

Christine McGourty 